\title{
DOENÇA MENTAL E CONTROLE SOCIAL: UMA RELEITURA A PARTIR DE MICHEL FOUCAULT
}

MENTAL DISEASE AND SOCIAL CONTROL: A REINTERPRETATION FROM MICHEL FOUCAULT

\section{José Manuel de Sacadura Rocha ${ }^{1}$}

\section{RESUMO}

Este artigo foca o Controle Social por meio da denominada Doença Mental a partir primordialmente do pensamento de Michel Foucault. Explora a tradição antipsiquiátrica e da psicologia social de diversos autores sob o ponto de vista da Cultura nas sociedades industriais mercantis. Defende-se a ideia de que o "relacionamento médico" com a "forma psíquica" e seu tratamento estão na "conformação" que existe entre a economia política e as formas derivadas como o político e sua manifestação pelo "poder". Conclui-se que os sujeitos, quando considerados doentios e tratados como perigosos, inserem-se como agentes de mecanismos que visam ao controle biopolítico de suas energias psíquicas, estabelecendo um estilo de vida que vai além das relações de produção e consumo, mas passa por elas.

Palavras-chave: Controle, Antipsiquiatria, Pós-estruturalismo, Biopolítica, Foucault

\footnotetext{
1 Possui bacharelado e Licenciatura em Ciências Sociais pela PUC/SP. É mestre em Administração de Serviços (IberoAmericana). Especialista em Meios Compositivos de Conflitos (ADR) - Mediação, Conciliação e Negociação (AASP). Especialista em Sistemas de Informação (Mauá de Tecnologia). Especialista em Marketing (ESPM). Pós-Graduado em Criminologia (ESMP). Doutorando em Educação, Arte e História da Cultura (Universidade Presbiteriana Mackenzie). E-mail: jsacadura@bol.com.br
} 
DOENÇA MENTAL E CONTROLE SOCIAL: UMA RELEITURA A PARTIR DE MICHEL FOUCAULT

\begin{abstract}
This article focuses on Social Control through the so-called Mental Illness based primarily on the thinking of Michel Foucault. It explores the antipsychiatric tradition and the social psychology of several authors from the point of view of Culture in the mercantile industrial societies. The idea is defended that the "medical relationship" with the "psychic form" and its treatment are in the "conformation" that exists between the political economy and the derivative forms like the political one and its manifestation by the "power". It is concluded that subjects considered to be unhealthy when treated as dangerous, are inserted as agents of mechanisms that aim at the biopolitical control of their psychic energies, establishing a lifestyle that goes beyond the relations of production and consumption, but goes through them.
\end{abstract}

Keywords: Control, Antipsychiatry, Post-structuralism, Biopolitics, Foucault

\title{
1 Introdução
}

Em 1961, Michel Foucault escreveu "A História da Loucura" e, em 1963, "O Nascimento da Clínica". Esses dois trabalhos se completam. No primeiro, o que sobressai, a contragosto da pesquisa oficial, é a importância do "doente" e da "loucura" - inversamente ao estudado habitualmente, a doença mental como personagem principal revela sua verdade, cujas circunstâncias atenuantes e agravantes expõem situações acima dos cânones e paradigmas institucionalizados pela "normalidade". Nesse âmbito, a verdade inaudita aflora revelando que o louco pode ser menos louco e que a sanidade não está necessariamente contida na teoria que se pretende verdade ao tratar dos apocalípticos desertores do cotidiano.

Historicamente, o louco nem sempre fora tratado como pessoa perigosa, perniciosa ou parasitária, cujo comportamento fosse sentido como ameaça, física ou moral, e cujo tratamento recebido devesse ser semelhante ao que a sociedade ocidental faz com a delinquência. "O Nascimento da Clínica" revela como o tratamento dado ao doente mental foi se modificando ao longo do tempo, passando de uma licenciosidade e mesmo acolhimento na maioria dos casos, para uma total intolerância mesmo em casos que não oferecem perigo algum para o corpo social. Segundo Foucault, o confinamento e as práticas mais invasivas e violentas contra o paciente considerado louco constituem um saber especializado a partir do século XVII e vão se desenvolvendo até atingir o ápice no final do século XVIII, formando então um conjunto de práticas médicas "aceitáveis" ainda que infligindo dor e temor ao paciente. Como isso é possível? É que, por detrás dessas práticas disciplinares, existe a construção 
de uma verdade própria do saber médico, que se prende a um conhecimento e tratamento que se nega a ser questionado enquanto conhecimento científico.

Esse conhecimento aparentemente produzido em bases sólidas de cientificidade passa a ser produzido de forma cartesiana, por experimentação laboral, com critérios metodológicos positivistas², e relega à segunda, terceira ou nenhuma instância a vida do paciente, as circunstâncias e os fatores próprios que podem estar por trás de comportamentos socialmente desviantes, mas que não são em si mesmos danosos ou destrutivos para ninguém. Na verdade, esse conhecimento médico especial é em si mesmo um dispositivo de vigilância e instrumento de disciplina social. "Esta experiência não é nem teórica nem prática. Ela pertence ao domínio dessas experiências fundamentais nas quais uma cultura arrisca os valores que lhe são próprios - isto é, compromete-os na contradição. $E$ ao mesmo tempo os previne contra ela" (FOUCAULT, 2008, p. 176).

Os conhecimentos que, a partir de meados do século XVII, adquirem o status de científicos apresentam duas características metodológicas fundamentais: eles são produto de experimentação e constituem-se em especializações de saber. Quanto mais se podem repetir as mesmas relações de coisas e fatos, independentemente de tempo e espaço, de lugar e hora, mais determinada verdade se torna absoluta e mais e mais podemos detalhar a área de conhecimento a que tais experimentos pertencem. Princípios imutáveis e métodos de experiência empíricos formatam paradigmas de verdade que moldam as explicações e as necessidades da vida coletiva. Mas aqui, logo de início, já se verificam, de forma disseminada e sob os auspícios da ilusória isenção científica, dispositivos e mecanismos disciplinares da vida social.

Quando chega a modernidade no século XVIII, e com a otimização dos sistemas industriais de produção a partir do século XIX, a mecanização e objetivação da vida aceleram a perda de dimensões de particularização e relevam contingências, contingências essas que poderiam lançar sobre a generalização do pensar e comportar e sobre o consequente "tratamento" interrogações e possibilidades alternativas à "unidimensionalidade" do existir (MARCUSE, 1982).

Não é por acaso que a objetivação e a universalização de conceitos e respostas levem sistematicamente as "histórias de vida" a serem desprezadas pelas ciências, inclusive pelas Ciências Humanas e Sociais em particular. A sociedade de massa precisava mais do que nunca que as instituições de produção de saber articulassem seus dispositivos de vigilância e controle de forma a manter intacto um núcleo de comportamentos desejáveis. Esses dispositivos disciplinares articulados formam uma trama de poder, que se apoia no saber desses mesmos dispositivos. Tal realidade permanece até nossos dias.

2 O positivismo é uma escola filosófica proposta por Auguste Comte (1798-1857), que, copiando as noções metodológicas das Ciências Naturais, propunha o estudo dos fenômenos sociais a partir de bases empíricas e pragmáticas, tais como a imutabilidade das causas, a relação atemporal e permanente entre causa e efeito, a isenção do pesquisador do objeto social estudado e, principalmente, a submissão do princípio dinâmico da sociedade (Progresso) ao princípio estático (Ordem). A filosofia positivista de Comte foi amplamente aceite pelos intelectuais e líderes quando da instauração da República no Brasil, motivo pelo qual a bandeira brasileira possui a frase "Ordem e Progresso". 
Foucault, na "História da Loucura", deixa evidente que essa obra se propõe a investigar os mecanismos que levaram à ruptura entre razão e desrazão, isto é, à estrutura da razão científica que preparou a oposição entre sentido e insensatez:

\begin{abstract}
A bela retidão que conduz o pensamento racional à análise da loucura como doença mental deve ser reinterpretada numa dimensão vertical; e neste caso verifica-se que sob cada uma de suas formas ela oculta de uma maneira mais completa e também mais perigosa essa experiência trágica que tal retidão não conseguiu reduzir (FOUCAULT, 2008, p.29).
\end{abstract}

O estabelecimento dessa divisão - desse "silêncio" promulgado de forma não casual pela supremacia da razão científica, experimental e laboratorial - cria práticas de verdade em diagnóstico e tratamento em relação às quais a psiquiatria, a psicologia e a psicopatologia não passam incólumes. Se Foucault vê o recrudescimento das práticas especializadas de recusa social e encarceramento, acompanhadas de tratamento clínico perverso e violento, no final do século XVIII, isso significa, antes de tudo, que essas práticas, de toda forma oriundas de relações de poder, são, elas mesmas, produto de um saber violento em uma sociedade tecnocrata violenta. Nunca como na passagem do século XVIII para o século XIX a loucura fora tratada dentro de uma estrutura de poder disciplinar própria, organizada coerentemente em uma estrutura científica com base na supremacia da razão.

A própria pobreza foi absorvida pelo hospital psiquiátrico, e as crises econômicas foram no século XVII, como ainda hoje, as grandes fornecedoras de internados. Como Foucault diz,

Ainda durante muito tempo a casa de correção ou os locais do Hospital Geral servirão para a colocação dos desempregados, dos sem trabalho, e vagabundos. Toda vez que se produz uma crise, e que o número de pobres sobe verticalmente, as casas de internamento retomam, pelo menos por algum tempo, sua original significação econômica (2008, p. 67).

A partir do século XIX, aliando-se a produção de saber ao tecnicismo de produção de massa, pessoas passam a serem diagnosticadas de forma "industrial", e, assim, atitudes e comportamentos que revelam descontinuidades e que podem questionar as verdades disciplinares tendem imediatamente a serem rechaçadas e arquivadas como impróprias e mesmo perigosas para a sociedade. Nesse sentido, o saber disciplinador é embalado para consumo como uma mercadoria desejada, um remédio para a crítica e os questionamentos desviantes da normalidade pretendida pelos poderes. As potencialidades das tecnociências são usadas pela tecnocracia como promessas para a felicidade geral. 
Mas fora dos períodos de crise, o internamento adquire outro sentido. Sua função de repressão vê-se atribuída de uma nova utilidade. Não se trata mais de prender os sem trabalho, mas de dar trabalho aos que foram presos, fazendo-os servir com isso a prosperidade de todos. A alternativa é clara: mão-de-obra barata nos tempos de pleno emprego e de altos salários; e em período de desemprego, reabsorção dos ociosos e proteção social contra a agitação e as revoltas (FOUCAULT, 2008, p. 67) ${ }^{3}$.

Não há motivos nem lugar para atitudes e práticas desviantes e tampouco para a eleição de objetos de estudo que vinguem um saber que questione essa disciplina. A partir de então, ainda que o poder e o saber se "transfigurem" em dispositivos de vigilância diversos, procurem disfarçar sua ânsia pelo autoritarismo e adquiram roupagens novas, na essência continuaram a celebrar um pacto de domesticação das vontades e de punição daquelas não domesticáveis. Jacques Ellul, sete anos antes, havia explicado:

Assim se completa o edifício desta civilização que não é um universo concentracionário, pois não há atrocidade, não há demência, tudo é níquel e vidro, tudo é ordem - e as rebarbas das paixões dos homens são cuidadosamente aparadas. Nada mais temos a perder e nada mais a ganhar, nossos mais profundos impulsos, nossas mais secretas palpitações do coração, nossas mais intimas paixões são conhecidas, publicadas, analisadas, utilizadas. Respondem a elas, põem à minha disposição exatamente o que eu esperava e o supremo luxo dessa civilização de necessidade, está em conceder-me o supérfluo de uma revolta estéril e de um sorriso de aquiescência (1968, p. 439).

O fato de assistir-se a um saber médico especializado sobre a loucura e o fato de o confinamento ser inquirido posteriormente não invalidam ou acabam com as formas modernas de disciplina social sobre o doente mental e seus congêneres, tanto do ponto de vista de sua utilidade como parâmetro para a normalidade quanto do ponto de vista de sua utilidade produtiva geral, já a partir do século XVIII.

As sociedades industriais modernas, nomeadamente as de livre mercado, precisam de mão de obra e de consumidores; hoje, mais consumidores que mão de obra. Mas é sobre vastos contingentes humanos que repousa a possibilidade da produção e do consumo. Trancafiar incontinentemente os indivíduos reduz essas potencialidades. Então, o poder eclesiástico, que fora no medievo o único detentor do saber a dedicar sua filosofia ao pastoreio de seu "rebanho", foi ao longo da Renascença se preparando e sendo preparado para se aliar a um saber científico - laico e preponderantemente classista -, que marcará a modernidade com uma pseudoliberdade: a troca da coletivização por individualizações facilitadoras de vigilância e controle.

3 Esse adentrar da mão de obra internada na estrutura produtiva começa por reduzir os salários dos trabaIhadores disponíveis no mercado, principalmente em tempos de crise econômica, e acaba por gerar desemprego, mesmo em tempos de pleno emprego, contribuindo, assim, de todas as formas, para a exploração da força de trabalho e a acumulação privada de riqueza. 


\begin{abstract}
Fala-se frequentemente que o Estado e a sociedade moderna ignoram o indivíduo. Quando observamos um pouco mais atentamente, ficamos surpresos, pelo contrário, com a atenção que o Estado dispensa aos indivíduos; surpreendemo-nos diante de todas as técnicas criadas e desenvolvidas para que o indivíduo não escape de forma alguma ao poder, à vigilância, ao controle, ao sábio, à reeducação nem à correção (FOUCAULT, 2006a, p. 54).
\end{abstract}

Tal tratamento da loucura e dos farrapos humanos de todos os tipos se alterou radicalmente em relação ao período do pastoreio eclesiástico da Idade Média, até aproximadamente o século XIII, quando o louco, o pobre, o mendigo e os de "desvio ideológico" eram na maioria das vezes vistos como possuídos por forças demoníacas, a serem salvos na força purificadora da confissão sob tortura e da fogueira. A loucura era mais uma classificação na hierarquia dos vícios e servia como tantas outras formas de manifestação, quase todas, para opor Satã a Deus e confirmar antinomia entre ambos.

Por vários séculos seguintes, na Renascença, apenas alguns casos extremos eram confinados e violentados física e moralmente, sendo na maioria das vezes incumbência das famílias o seu acolhimento, ou eram simplesmente deixados livres vagando pelos campos e pelas ruas dos insipientes burgos. A Renascença, até o século XVI, experimentou a loucura e mesmo as experiências mais devassas como um simbolismo de libertação: a liberdade em prol do saber que havia sido expurgado no episódio da árvore do conhecimento do paraíso. Em oposição à hierarquia e condenação dos vícios infernais do cristianismo, "um objeto novo acaba de fazer seu aparecimento na paisagem imaginária da Renascença; e nela, logo ocupará lugar privilegiado: é a Nau dos Loucos, estranho barco que desliza ao longo dos calmos rios da Renânia e dos canais flamengos" (FOUCAULT, 2008, p. 9).

Antes que a loucura seja usada de novo como artifício de domesticação e punição, por outros meios e renovadas formas de atrocidades - que não a tortura e a fogueira medievais, mas as sevícias e perversões científicas dos hospitais - no século XVII, ela experimenta uma valorização inaudita, a de servir ao intento renascentista de colocar o homem no centro das causas e olvidações, para o bem e para o mal, da vida.

Tanto na "História da Loucura" quanto em "O Nascimento da Clínica", vê-se como, a partir do século XVI e principalmente no século XVII, inaugurase a prática de internação geral devido ao empobrecimento e desemprego maciço da população europeia, resultando em uma população flutuante em toda a Europa, no meio da qual os próprios loucos foram aprisionados.

A sociedade disciplinar já requisitava os dispositivos do conhecimento científico para o controle social!

Com o advento da modernidade, a partir do século XIX, se vê o poder tomar uma atitude científica de saúde pública, em que o hospício é o lugar de tratamento dos assim considerados doentes mentais e em que, portanto, 
um saber especializado, a psiquiatria, podia dispor desses corpos e desses espíritos para exercer sua metodologia saneadora. Todavia, tais práticas de confinamento e violento tratamento dos que apresentam comportamentos "patológicos" são mais do que visões e práticas médicas de uma época; são, como Foucault considerou, formas disciplinares relacionadas com a dominação política da burguesia e, portanto, ações pertinentes de formações econômicas industriais e de mercado.

$E$ o que se chama Homem, nos séculos $X I X$ e $X X$, nada mais é que a espécie de imagem remanescente dessa oscilação entre indivíduo jurídico, que foi o instrumento pelo qual em seu discurso a burguesia reivindicou o poder, e o indivíduo disciplinar, que é o resultado da tecnologia empregada por essa mesma burguesia para constituir o indivíduo no campo das forças produtivas e políticas (FOUCAULT, 2006b, p. 72).

\section{Sociedade e doença mental}

Outros autores debruçaram-se sobre o tema, fazendo coro com Michel Foucault. Entre eles, citamos Thomas S. Szasz:

A agressão da sociedade, em geral, e de seu agente-médico, em particular, contra o chamado insano, começa no século XVII, com a masmorra, as correntes, a tortura física e a fome; continua nos séculos XVIII e XIX, com o manicômio, as surras, as sangrias e as camisas-de-força físicas, chamadas coletes; expande-se no século $X X$, com seu imenso hospital psiquiátrico estadual (que abriga até 15.000 internados), a máquina de choques, o leucótomo (o bisturi para separar o lobo frontal do resto do cérebro) e as camisas-de-força químicas, chamadas tranquilizantes. Como todas as formas sistemáticas e popularmente aceitas de agressão, a violência psiquiátrica é autorizada por importantes instituições sociais, e nelas incorporadas, além de ser sancionada pela lei e pela tradição. As principais instituições sociais que participam de teoria e prática da violência psiquiátrica são o estado, a família e a profissão médica. O estado autoriza o encarceramento involuntário de doentes mentais 'perigosos'; a família aprova e usa essa regra; a profissão médica, através da psiquiatria, administra a instituição e apresenta as justificativas necessárias para ela (1976, p. 316).

Contemporaneamente, a moderna indústria farmacêutica, ao colocar no mercado uma série prodigiosa de medicamentos orientados para o "tratamento" das doenças psíquicas, se, por um lado, evita que muitas vezes indivíduos sejam alvo de práticas de confinamento e agressividade em instituições psiquiátricas, por outro lado, retira, no mais das vezes, a potencialidade da existência diferente e da atitude que contesta a "unidimensionalidade" a que estamos sujeitos no mundo industrial moderno (MARCUSE, 1982). 
A potencial perda de produtividade e consumo de pessoas internadas em hospícios acabou por reforçar a indústria química de psicotrópicos a partir do final da Segunda Grande Guerra, orientando o financiamento à pesquisa e produção em massa desse tipo de remédio. Ao mesmo tempo em que liberta a mente e o espírito da crítica e do peso da escolha, os medicamentos modernos "domesticam" os indivíduos, submetidos não ao respeito de suas histórias e experiências, mas a uma atomização, a uma individualização insignificante que interessa à manipulação que o sistema faz de cada pessoa. Estamos na esfera da Biopolítica! Saímos do fogo e pulamos na fogueira!

A psicoterapia que opera a partir do conhecimento de si vem, não raro, acompanhada de doses maciças de química que domestica a partir do que está "fora de si". Isso não quer dizer, obviamente, que não existam momentos em que procedimentos médicos próprios não sejam necessários em casos de comprovada doença mental, mas não como princípio de uma especialidade de intervenção sociopolítica para o comportamento de massa a impedir rupturas e descontinuidades.

$\mathrm{Na}$ origem da maioria dos males infligidos aos doentes mentais, está a errônea e perversa identificação entre fisiologia e mente, consequência da esdrúxula identificação entre cérebro - órgão do corpo - e mente - entidade espiritual. Fica fácil compreender por que o tratamento psiquiátrico e psicológico moderno remete de forma permanente a diagnósticos médicos positivistas, que veem todas as manifestações psíquicas como doenças somáticas. Ainda que muitas vezes determinadas manifestações psíquicas pareçam invadir os limites da doença somática, quando pensamos em tais ocorrências como manifestações da mente, é preciso aceitar fatores perturbadores éticos, políticos, religiosos e sociais, em relação aos quais a medicina e os médicos têm pouca familiaridade e competência para abordar.

A incidência de tais fatores perturbadores na psique do homem contemporâneo o leva a uma situação extrema de insegurança e isolamento, cuja solução é a submissão a tudo o que possa lhe aliviar o sofrimento, mesmo à custa de sua liberdade. Erich Fromm manifesta-se nesse sentido:

Por outra parte, se as condições econômicas, sociais e politicas, das quais depende todo o processo de individualização humana, não oferecem uma base para a realização da individualidade no sentido que se acaba de falar, ao mesmo tempo em que se priva aos indivíduos aqueles vínculos que lhes outorgam segurança, a falta de sincronização que daqui resulta transforma a liberdade em uma carga insuportável. Ela se identifica então com a dúvida e com um tipo de vida que carece de significado e direção. Surgem assim poderosas tendências que levam para o abandono deste gênero de liberdade para buscar refugio na submissão ou em alguma espécie de relação com o homem e o mundo que prometa aliviar a incerteza, ainda que prive o individuo de sua liberdade (2002, p. 53, tradução nossa). 
Em circunstâncias de grassante inabilidade, ou de total desinteresse para uma abordagem menos clínica, é óbvio que toda a manifestação psíquica que foge aos padrões "normais" é tratada de forma mais fácil e cômoda como doença, assim como um resfriado ou um câncer. Por mais inacreditável que possa ser, o pensamento científico moderno resiste, ainda hoje, a aceitar que exista diferença entre doença somática e psíquica.

O fato de contemporaneamente a indústria farmacêutica ter desenvolvido drogas capazes de minimizar o sofrimento mental ou mesmo de anestesiar o corpo e solapar a vontade da mente não modificou a perspectiva de análise da medicina e dos médicos sobre as manifestações sociais da mente; pelo contrário, confirma a ruptura entre razão (sadia) e desrazão (doença).

De acordo com esse modelo médico, as doenças são somáticas ou psíquicas, o mesmo valendo em termos de tratamento. Portanto, qualquer fenômeno psicológico pode ser visto como doença mental ou psicopatologia, e qualquer intervenção psicológica como uma forma de tratamento mental ou psicoterapia. A única alternativa viável para essa perspectiva familiar, mas falsa, seria abandonar todas as abordagens médicas da doença mental e substituí-las por outras que se adequassem aos problemas éticos, políticos, psicológicos e sociais que sofrem os pacientes psiquiátricos, e que os psiquiatras ostensivamente procuram curar (SZASZ, s/d, p. 86).

A incapacidade de tratar, na maioria dos casos, as manifestações psíquicas como não doença parte da intolerância e do fanatismo na crença de que existe um padrão de comportamento aceitável e desejável em uma sociedade, um comportamento "normal". Essa normalidade, contudo, é construída pela dialética estabelecida com a loucura, uma vez que é a partir dela que a consciência pode pensar sobre si mesma e se verificar como sã ou insana. É por isso que Foucault afirma que "A loucura é um momento difícil, porém essencial, na obra da razão; através dela, e mesmo em suas aparentes vitórias, a razão se manifesta e triunfa. A loucura é, para a razão, sua força viva e secreta" (2008, p. 35). Nesses termos, muitas vezes a loucura é a desrazão a partir da qual a razão se reconhece e normaliza, e não o inverso como muitas vezes se supõe.

A Sociologia moderna sugeriu que essa normalidade deve ser definida dentro de certos limites estabelecidos como regras e direito, base para a convivência social em determinado momento histórico. A tese sociológica de que o "comportamento normal" é todo aquele que se "comprime" entre os limites normativos de uma sociedade em determinado momento histórico, confundindo-se com a apresentação de características gerais que constituem o observado no comportamento social médio, foi defendida como conceito na Sociologia a partir de Emile Durkheim:

Chamaremos normais os fatos que apresentam as formas mais gerais, e daremos aos outros o nome de mórbidos ou patológicos. 
Se decidirmos chamar de tipo médio um ser esquemático espécie de individualidade abstrata - construído pela reunião num mesmo todo, dos caracteres mais frequentes da espécie em suas formas mais habituais, poder-se-ia dizer que o tipo normal se confunde com o tipo médio e que todo desvio com relação a esse padrão de saúde é um fenômeno mórbido (2002, p. 48).

Essa definição deixa claro que o "patológico" se define em relação ao que se considera como "saúde", e vice-versa, mas nunca in abstracto, "nem de forma absoluta". Ao mesmo tempo, tais regras e padrões estão relacionados com os meios e as formas concretas de reprodução dos bens materiais necessários à sobrevivência da comunidade, o que acarreta em mudanças lentas, sempre sobrepesando as possibilidades de destruição do corpo social e a capacidade que este possui de enfrentar as circunstâncias e as consequências das descontinuidades e rupturas. Portanto, sob uma perspectiva sócio-histórica, o "medo" determina se um comportamento indesejável pode ser considerado "normal" ou, em outras palavras, se pode estar contido pelas linhas limites da convivência social. Mesmo Durkheim tinha essa convicção quando afirma que:

Com efeito, não é mais possível contestar hoje que não apenas o direito e a moral variam de um tipo social para outro, mas ainda que eles se modificam num mesmo tipo se as condições de vida coletiva se modificarem. Porém, para que estas transformações sejam possíveis, é preciso que os sentimentos coletivos que estão na base da moral não sejam refratários à mudança e não apresentem, por conseguinte, senão uma energia moderada (2002, p. 61).

Este pormenor, de que a normalidade pode ser indesejável, é combatido na arguição de Erich Fromm (na obra "Psicologia da Sociedade Contemporânea") quando acusa o relativismo sociológico de considerar como aceitável, do ponto de vista da sanidade social, o indesejável como normal. Ele acredita que assim se inviabiliza a percepção de que a sociedade industrial moderna, notadamente a de livre-mercado, sofre de uma neurose, de uma psicopatologia.

Em contraposição, a tese de sociedade patologicamente doente inverte o peso e a responsabilidade pela saúde mental, na medida em que, se a sociedade é que está doente, o homem moderno deixa de ser o culpado pela falta de saúde mental e pela "neurose social". Não é o conjunto de homens doentes que fazem a sociedade doente, mas a sociedade doente que provoca a falta de saúde mental nos homens. Fromm constrói seu humanismo formal em bases concretas e absolutas, isto é, nas motivações da "neurose coletiva", partindo da realidade socioeconômica e política em que a sociedade se encontra estruturada, ainda que considere que o homem "não é uma folha de papel em branco na qual a cultura escreve seu texto" (1984, p. 81).

Neurose pode ser definida como um estágio mental que situa o indivíduo entre o imaginário e o real. A neurose é, normalmente, uma concessão da 
mente que se acomoda transferindo a realidade para um fantasma, um mito ou um ritual. Edgar Morin, trabalhando com o fenômeno de "cultura de massa", diz que os indivíduos vivem em um espaço "espetacularizado" e que é a relação midiática com as modernas tecnologias de comunicação que forma a noção de ética e estética.

Assim, feita de modo estético, a troca entre o real e o imaginário é, se bem que degradada (ou ainda que sublimada ou demasiado sutil), a mesma troca que entre o homem e o além, o homem e os espíritos, ou os deuses que se fazia por intermédio do feiticeiro ou do culto. A degradação - ou o supremo requinte - é precisamente essa passagem do mágico (ou do religioso) para a estética (MORIN, 1984, p. 78).

Contudo, a estrutura socioeconômica é apenas um "polo" a moldar o caráter dos indivíduos, haja vista que existe uma natureza humana formada por propriedades psíquicas e fisiológicas muito particulares, conforme Erich Fromm nitidamente sublinha: “Em outras palavras, as condições sociais exercem influências sobre os fenômenos ideológicos através do caráter; este, por sua parte, não é o resultado de uma adaptação passiva às condições sociais, senão uma adaptação dinâmica que se realiza sobre a base de elementos biologicamente inerentes à natureza humana ou adquiridos como resultado da evolução histórica" (2002, p. 282).

Logicamente, se existe uma sociedade neurótica e com outras patologias congêneres, deve existir um tipo de sociedade capaz de produzir nos cidadãos saúde mental. Nesses termos, Fromm acaba por definir o que seria necessário para que a sociedade fosse sadia, condição para a construção da saúde mental entre os indivíduos:

Independentemente de falarmos de 'saúde mental' ou de 'desenvolvimento maduro' da espécie humana, o conceito de saúde mental ou de amadurecimento é um conceito objetivo a que chegamos pelo exame da 'situação humana' e das necessidades e exigências dela emanantes. Segue-se daí [...] que a saúde mental não pode ser definida em termos da 'adaptação' do indivíduo à sua sociedade, mas que, pelo contrário, deve ser definida como adaptação da sociedade às necessidades do homem, pelo seu papel em impulsionar ou impedir o desenvolvimento de saúde mental. O fato de o indivíduo estar ou não mentalmente sadio não é primordialmente um assunto individual, pois depende da estrutura da sociedade. Uma sociedade sadia desenvolve a capacidade do homem para amar o próximo, para trabalhar criadoramente, para desenvolver sua razão e sua objetividade, para ter um sentimento de si mesmo baseado em suas próprias capacidades produtivas. Uma sociedade insana é aquela que cria hostilidade mútua e desconfiança, que transforma o homem em instrumento de uso e exploração para outros, que o priva do sentimento de si mesmo, salvo na medida em que se submete a outros ou se converte em um autômato (1984, p. 73-74). 


\section{3 doença mental e controle social}

A nosso ver, no entanto, a Sociologia, ao definir o indesejável como normal - dentro dos limites em que uma sociedade comporta certos comportamentos e estabelece regras de aceitação e punição para os mesmos -, não estava responsabilizando os indivíduos ou "adoecendo-os", tampouco querendo retirar a responsabilidade sociopolítica da neurose coletiva. Pelo contrário, essa afirmação pode ser entendida como denúncia de que a normalidade aceita comportamentos indesejáveis e os normatiza juridicamente, exatamente porque está incapacitada modernamente de prevenir e combater suas patologias estruturais ${ }^{4}$.

A consequência que se tornará mais relevante na proposta de Foucault, ao estudar a loucura e a clínica psiquiátrica, é o fato de que essa normalidade é instrumento de controle social e formação de um poder disciplinar recente. O que é normal, tanto quanto os limites em que essa normalidade se encontra, apresenta formas diferentes na história. E, se sempre existiu uma concepção de "normal", igualmente sempre houve uma ideia de "anormalidade". Assim, ainda que os limites onde se estabelecem tais conceitos se modifique ao longo do tempo, o fato é que existe uma história a ser contada pela normalidade ou pela anormalidade, pela sanidade ou pela insanidade, na proporção em que a razão se mede com a loucura.

Cada uma dessas formas de consciência é ao mesmo tempo suficiente em si mesma e solidária com todas as outras. Solidárias porque não podem deixar de apoiarem-se sub-repticiamente umas nas outras; não há um saber da loucura, por mais objetivo que pretenda ser, por mais baseado que afirme estar nas formas do conhecimento científico e apenas nelas, que não proponha, apesar de tudo, o movimento anterior de um debate crítico onde a razão se mede com a loucura, experimentando-a ao mesmo tempo na simples oposição e no perigo da reversibilidade imediata (FOUCAULT, 2008, p. 169).

O fato de funcionalmente se escolher estudar e explicar os homens a partir daquilo que se considera em determinado momento normal ou sadio pode ser explicado, primeiro, pelo grau da capacidade do corpo social lidar com

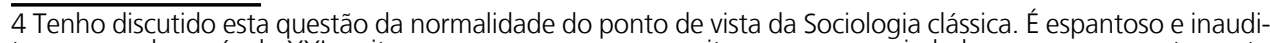
to que em pleno século XXI muitas pessoas se recusem a aceitar em nossa sociedade que um comportamento anômico, por mais condenável que possa ser não seja ainda assim "normal". Só tenho uma explicação: a neurose e esquizofrenia em que vivemos nos compelem a produzir incessantemente bodes-expiatórios. Recusamo-nos a aceitar que fomos capazes de produzir coletivamente a capacidade de produzir e conviver com a aberração! Este fato, o de que sabemos viver com esses comportamentos indesejáveis, os torna, afinal, parte de nosso cotidiano, a "anomia" como "normal". A negação desse fato não nos torna mais saudáveis, pelo contrário, cria em nós a psicose da retaliação, da punição, do ódio, e para alimentar nosso ódio continuamos a conviver com práticas odiosas de perseguição, de punição, de exclusão; nessa ciranda de degradação alimentamos nossas patologias para além de rejeitarmos apenas os comportamentos sabidamente nocivos: estendemos nossa neurose e psicose a tudo e todos. Deixo isso claro em várias oportunidades, por exemplo: "Ora, se o comportamento, por anomia, se desraigou demais do comportamento médio esperado, até chegar a ir além do máximo que a sociedade já estabeleceu como limite às estratégias de sobrevivência, então algo fracassou em todo o processo de sociabilização e na agenda que o grupo social impõe de comportamento aos seus membros, não só pelo favorecimento da anomia, mas pela incompetência em desenvolver alternativas à exclusão endógena da moderna divisão do trabalho" (SACADURA ROCHA, 2015, p. 78).
} 
o mal-estar provocado por acontecimentos dissidentes e, depois, pelo grau de amadurecimento social em perder o medo da descontinuidade revelada na necessidade de autonomia e liberdade em relação às estruturas sociais. De qualquer forma, a virtude da modernidade foi, por meio de conhecimentos humanos específicos, disseminar dispositivos de controle por todo o corpo social, sob o aval da ciência articulada em uma trama de poder extensa.

Geralmente, a história oficial é construída pela normalidade que atende à funcionalidade de estruturas sociais que se movem muito lentamente. Nesse sentido, a crítica social e a possibilidade de rupturas mais reveladoras de outras realidades se dão mais fortemente no nível dos fatos e comportamentos autônomos de indivíduos "ímpares" e de acontecimentos anômicos diferenciados e esparsos.

Fica evidente, pois, a necessidade de abandonar a noção de um homem genérico e universal em sua plasticidade psíquica e fisiológica; deve-se "alargar" a noção de uma sociedade perfeita que possa produzir estruturalmente, econômica e politicamente uma saúde mental igualmente universal, mesmo que seja pelo padrão médio.

Entretanto, a separação científica entre "razão" e "loucura" permanecerá enquanto se acreditar na possibilidade de constituir um "homem sadio", inclusive a partir de práticas sociais e estruturas tidas como adequadas para o desenvolvimento em plenitude de suas faculdades físicas e mentais. É plausível acreditar que a preocupação com a saúde na época clássica greco-romana possa ter reforçado a ideia universal com a qual estamos acostumados a diagnosticar doença mental. No entanto, essa preocupação com a saúde e a beleza física na Antiguidade clássica é permeada por diversas orientações e limitações (conferir "Carta Sobre a Felicidade: a Meneceu", de Epicuro, e "Meditações", de Marco Aurélio) que não indicam uma fobia com relação a comportamentos incomuns, tachados como doença; pelo contrário, indicam a "liberdade" dos com aparente desrazão que estão inseridos publicamente no meio social.

A ideia de um homem universal com necessidades materiais comuns, só conquistadas no plano da convivência produtiva coletiva, tem alimentado prematuramente, tanto nos adeptos da sociedade de mercado quanto nos adeptos de certo socialismo, a noção errônea de que a saúde mental pode ser objetivamente identificada e classificada. Isso reforça a primazia de uma razão normal e sadia em contrapartida a manifestações psíquicas tidas como doença: depressão, obsessão, neurose, histeria, esquizofrenia e psicose - tudo devidamente catalogado como loucura.

As instituições disciplinares que regulam a separação entre normalidade racional e insanidade, principalmente quando esta possa eventualmente ser indesejável, servem a estruturas e mecanismos de controle social, ou, na ótica de Foucault, a estruturas de poder. Normalidade, razão, saber e poder, para dizer e controlar o que razão "não é". Se for pesquisado o critério de saúde e insanidade na história, com toda certeza, verificar-se-á sua relação com o 
nível de maturidade psíquica do corpo social - medo, frustração, angústia e experiências traumáticas -, em "consonância" com as necessidades de desenvolvimento produtivas. Isso quer dizer que a história de controle social ou do poder é também a história da domesticação das vontades e que a psicologia social nas sociedades liberais de livre concorrência precisa de um quantum de "normalidade dos acontecimentos da desrazão", nos mesmos moldes com que a "forma mercadoria" se reproduz em termos de quantidades e unidades, trocas e relações jurídicas próprias das sociedades mercantilizadas.

Nesse caso, no mundo dos "valores de troca", não restam dúvidas de que um indivíduo "normal e são" precisa do outro que é "anormal e insano". Uma sociedade dita "sensata" inventa e reinventa dentro de suas entranhas a "insensatez". A "cura" forja a "doença". O bode-expiatório é constitutivo da história social humana: outrora a feiticeira, hoje o louco, amanhã, quiçá, o psiquiatra5!

Não há como negar a contribuição lúcida e singular de autores como Vygotski, Fromm, Marcuse, Maffesoli ou Silvia Lane, que procuraram introduzir na psicologia social a ideia forte que a constituição do Ser, sua personalidade e sua elaboração psíquica não podem ser separadas da cultura, da realidade social, das condições concretas e das relações sociais pelas quais se reproduz sua existência.

\begin{abstract}
O indivíduo sujeito da história é constituído de suas elações sociais e é, ao mesmo tempo, passivo e ativo (determinado e determinante). Ser mais ou menos atuante como sujeito da história depende do grau de autonomia e de iniciativa que ele alcança. Assim ele é história na medida em que se insere e se define no conjunto de suas relações sociais, desempenhando atividades transformadoras destas relações; o que implica, necessariamente, atividade prática e inteligência, tão inseparáveis quanto, no nível da sociedade, são inseparáveis a infra e a superestrutura, e cuja unidade é estabelecida por um processo cujo agente exclusivo é a atividade humana em suas diferentes formas (LANE, 1989, p. 40).
\end{abstract}

Contudo, há que se perceber essa "atividade" mais que a "passividade", pois é nos rasgos de exceção e conduta inaudita que o homem se agiganta diante da natureza e dos outros animais. No entendimento do comportamento mais "enervado" como coisa que parte dessa "atividade determinante", reside toda a diferença entre a depreciação do doente mental e sua consideração como agente de um mundo onde ele também faz parte e se constitui pela relação com o normal. Não sendo assim, não apenas toda uma filosofia prepositiva de orientação coletivista - de Aristóteles a Marx - se perderá nas brumas da submissão do homem às suas determinações objetivas e materiais

\footnotetext{
5 "Mas o ilustre médico, com os olhos acesos de convicção científica, trancou os ouvidos à saudade da mulher, e brandamente a repeliu. Fechada a porta da Casa Verde, entregou-se ao estudo e à cura de si mesmo. Dizem os cronistas que ele morreu dali a dezessete meses, no mesmo estado em que entrou, sem ter podido alcançar nada. Alguns chegaram a ponto de conjeturar que nunca houve outro louco, além dele, em Itaguaí; mas esta opinião, fundada em um boato que ocorreu desde que o alienista expirou, não tem outra prova, senão o boato; e boato duvidoso, pois é atribuído ao padre Lopes, que com tanto fogo realçara as qualidades do grande homem. Seja como for, efetuou-se o enterro com muita pompa e rara solenidade" (ASSIS, 2006, p. 133)
} 
da produção, o que definitivamente não é o pensamento que pretende ir além do liberalismo mercantilizado. Na concepção de Michel Foucault, o divisor de águas entre seu pensamento e demais autores, bem como entre a mercantilização da vida e a vida boa para todos, é o "poder".

Vejamos, entretanto, o que afirma Stuart Hall em "A Identidade Cultural da Pós-modernidade", sobre o pensamento de Karl Marx e por extensão sobre a filosofia marxiana:

A primeira descentração importante refere-se às tradições do pensamento marxista. Os escritos de Marx pertencem, naturalmente, ao século $\mathrm{XIX}$ e não ao século $\mathrm{XX}$. Mas um dos modos pelos quais seu trabalho foi redescoberto e reinterpretado na década de sessenta foi à luz de uma afirmação de que os "homens (sic) fazem a história, mas apenas sob as condições que lhes são dadas". Seus novos intérpretes leram isso no sentido de que os indivíduos não poderiam de nenhuma forma ser os "autores" ou os agentes da história, uma vez que eles podiam agir apenas com base em condições históricas criadas por outros e sob as quais eles nasceram, utilizando os recursos materiais e da cultura que lhes foram fornecidos por gerações anteriores (2004, p. 34-35).

A passagem a que Hall se refere é o famoso parágrafo introdutório de Marx na obra "O 18 Brumário de Luís Bonaparte", em que Marx, a pedido, tenta explicar a ascensão ao poder do sobrinho de Napoleão Bonaparte - Luís Bonaparte, que deu um golpe em 1851, após as revoltas populares de 1848 -, algo estranho não só pelas dúvidas quanto à sua origem verdadeira, mas também porque este governante, vindo das mais baixas classes francesas, estava ali por influência da burguesia, mesmo colocando nos altos escalões do governo pessoas de sua classe de origem, o que parecia contradizer os interesses do capital. A interpretação posterior a que Hall se refere se deve a Louis Althusser (na obra "Por Marx"), que resgatou com brilhantismo o método histórico de Marx, a partir da segunda metade do século XX, engajando novas gerações de admiradores da obra marxista.

O problema, a nosso ver, é que Hall não só tira o contexto das palavras de Marx, como deduz de um pequeno trecho que o pensamento de Marx leva, por vias da concretude material da produção, nas relações sociais ali estabelecidas, e diante das capacidades técnicas do momento histórico, a um empirismo onde os homens são passivos e "não poderiam de nenhuma forma ser os "autores" ou os agentes da história". Isto levaria Althusser a um "anti-humanismo teórico". Primeiro, dizer que os homens fazem a história sob determinadas condições concretas materiais não significa que os homens não façam a história: Marx começa o parágrafo afirmando isto com clareza: "Os homens fazem sua própria história, mas não a fazem como a querem" (1980, p. 203).

Segundo, distante do idealismo filosófico, o que temos aqui é a herança de uma filosofia materialista histórica dialética, não apenas "materialista", 
DOENÇA MENTAL E CONTROLE SOCIAL: UMA RELEITURA A PARTIR DE MICHEL FOUCAULT

mas dialética e histórica: o homem é o agente da história desde o primeiro momento, na mediação - com a natureza -, e na associação - com os outros - das coisas e dos outros consigo mesmo; quando faz os instrumentos de trabalho e se emancipa de sua biologia precária; quando estabelece as relações de produção e demais da existência em geral; quando estabelece os limites da moralidade, da religião, das regras de direito etc.; e quando reflete sobre si, sobre os outros e sobre sua posição no universo, pois o próprio pensamento se dá pela cultura e pelo social. Nas palavras de Lev Vygotski: “Portanto, a personalidade que é um conceito social, abarca e sobrepõe o natural, o histórico no ser humano" (1995, p.328).

A história está tão presente na economia política, e o homem, tão ativo nela como seu produtor, "O indivíduo sujeito da história é constituído de suas relações sociais" (LANE, 1989, p. 40), que Althusser afirmou que Marx inaugurou um "Continente-História", só comparado ao "Continente-Matemáticas" dos gregos e ao "Continente-Física" de Galileu. O erro de Hall é não considerar que o processo material é histórico e dialético, ou seja, desconhecer o método marxiano; o erro é não mencionar, precisamente, todo o esforço que os pósmarxistas, a partir de Althusser, têm feito para relacionar a superestrutura cultural e as demais manifestações espirituais do homem à estrutura fundante da economia, fundante, mas não determinante, pelo menos como o sabemos desde Gramsci (conferir "Escritos Políticos" e "Os Intelectuais e a Organização da Cultura") ou desde o que Althusser chamou de "sobredeterminação" (conferir "Por Marx").

\section{Releitura}

Não se pode trabalhar com o fenômeno da "doença mental" culturalmente tomado sem o localizar nos momentos históricos da existência humana e desvinculado de suas necessidades econômicas, políticas e sociais. Defendemos, neste trabalho, que o relacionamento médico com a "forma psíquica" e seu tratamento estão na "conformação" que existe entre a economia política e as "formas derivadas" como o político - "forma poder" em Foucault. Essa "relação", portanto, se dá por vias da historicidade humana. Nas palavras de Ronald Laing: "Los hombres han estado sujetos, en todas las épocas, como ellos creían o experimentaban, a fuerzas provenientes de las estrellas, de los dioses, o a fuerzas que se introducen hoy em nuestra sociedad, apareciendo tal como lo hacían antes las estrellas, para determinar el destino humano" (1977, p. 26).

De forma alguma, contudo, afirmamos que o comportamento mental diferenciado não seja em si mesmo "próprio" e "singular", espetacular e produtor de diferenciações e reclamações em relação ao status quo médico. Mas, também, se é possível que esses comportamentos, que insistimos em chamar de anormais ou de doença mental, conforme os cânones da medicina se anteponham e confrontem à tradicionalidade da "normalidade" e classificação 
do "saudável" como tal, isso significa que existe um porém, um "porque" que justifica essa classificação de sadio em oposição à doença mental. Mas tal distinção, conforme os ícones de normalidade médica, não se dá a esmo e fortuitamente, mas com relação a pressupostos e predicados bastante concretos e empíricos nas formações de organização econômica, política e cultural específicas ao longo da história. Isso quer dizer que a "personalidade" e seus "desvios", quando considerados doentios e tratados como "perigosos", inserem-se na reprodução de um estilo de vida e determinado olhar sobre o humano e sua relação social. Por outro lado, concomitantemente, denunciam algo muito sério no modus vivendis, não in abstract, mas in absentia.

Assim, esperamos que não nos entendam como aqueles que defenderiam exclusivamente a determinação da economia sobre as manifestações psíquicas disruptivas; acreditamos, contudo, que tais manifestações são o sintoma de que algo não está correto na epistemologia tradicional e de que algo não está funcionando adequadamente no mundo real, especialmente nas sociedades industriais mercantis modernas. Se se tem maltratado e violentado os portadores de "doenças mentais" é mais porque estes se abstêm de participar da "insanidade da normalidade mercadológica", do que por qualquer consideração mais científica ou lógica na produção do conhecimento, ainda que falseando se afirme o contrário, por vias de um purismo e elitismo próprios das ciências positivas modernas. Defende-se, portanto, neste breve estudo, que esses comportamentos quando não alijados e medicados inadequadamente, podem contribuir para uma humanidade mais salutar.

Foucault, ao enfatizar a "forma política" pelo instrumento do poder, não deixou de efetuar a relação derivada da economia - "forma mercadoria" com a doença mental - "forma psíquica" -, basta que se veja a intencionalidade colocada em seus textos arqueológicos: "História da Loucura", "O Nascimento da Clínica", "Vigiar e Punir: o nascimento da prisão" e "História da Sexualidade". Foucault mostrou magistralmente que, nas sociedades industriais modernas, a disciplina tinha o propósito de agenciar - por vias estatais e por vias das "instituições totais" (microfísica do poder), como os hospícios, as prisões, os quartéis, as casas de correção e as escolas - o homem, enquanto detentor de forças e energias psíquicas extraordinárias e que tal agenciamento, controle e logística dos corpos exigiam uma domesticação das vontades e dos comportamentos estandardizados próprios das necessidades logísticas mercantis (produção, circulação $r$ consumo), enfatizando que era pelo poder - "forma política" - que essa sujeição e objetivação se afirmavam (biopolítica). Se a doença mental se insere na dimensão própria da saúde, isso significa que Foucault estabeleceu uma correlação entre as diversas formas da superestrutura social - política e medicina, política e psique, política e cultura, política e ciência, política e segurança pública, política e jurídico -, entendendo-se política como "o poder" nessas relações. Todavia, tais relações, na dimensão superestrutural, estão em (com)formação umas com as outras, 
mas todas em (com)formidade, por derivação, com a estrutura econômica (produção, circulação e consumo), desde que se entenda aqui a vida social por uma verdadeira conexão dialética.

Já se sabe, por tantos que o disseram, das letras e do povo, que todo o consenso é possivelmente descartável e perigoso. É verdade que se confunde amiúde consenso e unanimidade. Enquanto o primeiro pressupõe discussão, dialética e argumentação, o segundo prevê um estado de concordância que pode não advir necessariamente do consenso. O fato relevante é que, mesmo pelo consenso, não está dito que o que todos acham correto seja verdadeiro ou esteja eticamente correto. $O$ mesmo se dá com relação à saúde mental: o fato de milhões de indivíduos aceitarem certo tipo de razão e de normalidade não significa que estejam sadios e que os demais sejam insanos ${ }^{6}$. Pelo contrário, na história pululam fatos e acontecimentos de grande vulto que são exemplos de insanidade coletiva e geral. A escravidão até bem pouco tempo foi uma prática de consenso aceita por sociedades inteiras, pelo menos por sua esmagadora maioria, sem que, contudo, se possa considerá-la justa, correta ou mesmo admissível.

Infelizmente, os homens estão sempre mais suscetíveis a aceitarem a injustiça e a serem inescrupulosos para se sentirem parte do grupo e da "normalidade", do que a denunciarem e abandonarem práticas aviltantes e desumanas sobre alguém, alguns ou mesmo muitos.

Talvez Espinoza tenha razão e seja possível construir dispositivos de autocontrole de nossos desejos ilimitados: "Todas as afecções de ódio são más; e, por conseguinte, aquele que vive sob a direção da Razão esforçarse-á, quanto puder, por conseguir não ser dominado pelas afecções de ódio, e consequentemente, esforçar-se-á também por que outrem não sofra as mesmas afecções. Mas o ódio é aumentado pelo ódio recíproco, e, ao contrário, pode ser extinto pelo amor de tal maneira que o ódio se converta em amor. Logo, aquele que vive sob a direção da Razão esforçar-se-á por compensar o ódio, etc., de outrem pelo amor, isto é, pela generosidade" (1983, p. 252).

Houve quem dissesse que Foucault negava a existência da loucura como doença. Longe disso, o pensamento foucaultiano afirma a existência da loucura, entendendo que porque ela existe realmente é possível estudála, dissecá-la e usá-la como pano de fundo para as práticas do poder: "[...] acharam que eu dizia que a loucura não existia, quando o problema era totalmente inverso [...]" (FOUCAULT, 2006a, p. 283).

Se não se trata de negar a loucura em si, como doença mental, por outro lado, é preciso atentar sempre para o fato de que a loucura e os graus de loucura que um indivíduo apresenta são sempre definidos pelo olhar do outro, do alheio a ele; "o doente mental se constitui como sujeito louco em relação e diante daquele que o declara louco" (FOUCAULT, 2006a, p. 275).

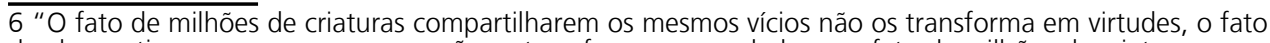
de elas praticarem os mesmos erros não os transforma em verdades, e o fato de milhões de criaturas compartilharem a mesma forma de patologia mental não as torna mentalmente sadias" (FROMM, 1984, p. 25). 
Na obra de Michel Foucault, o que sobressai é que esse tipo de comportamento gera e "usina" tipos de poder aliados de mecanismos sociais e estruturas - dispositivos disciplinares - de saberes pulverizados pelo corpo social, o que caracteriza, do ponto de vista tanto do saber quanto do poder, a história social moderna em correlação com a produção e o consumo de mercadorias.

E podemos resumir toda essa mecânica da disciplina dizendo o seguinte: o poder disciplinar é individualizante porque ajusta a função-sujeito à singularidade somática por intermédio de um sistema de vigilância-escrita ou por um sistema de panoptismo pangráfico que projeta atrás da singularidade somática, como seu prolongamento ou como seu começo, um núcleo de virtualidades, uma psique, e que estabelece além disso a norma como princípio de divisão e a normalização como prescrição universal para todos esses indivíduos assim constituídos (FOUCAULT, 2006b, p. 69).

E como dizer, com que direito, a partir de qual realidade, de quais fatos e de qual verdade, à mente que não se vê doente, que ela o está? Por todo o lado, as ciências e as tecnologias emprestam o status de verdade aos mais variados fenômenos no sentido de fortalecer e recriar essa verdade, esse direito, essa sanidade. Obviamente, quanto mais discrepantes, destoantes e imaginativos os movimentos, mais a prática psiquiátrica se esmera em anular a vontade mental anárquica do louco e em impor, de fora, a doença ou o seu reconhecimento como tal. A parte mais fundamental da internação, da vida hospitalar e do corpo médico está exatamente em submeter e hostilizar o "doente" para que este execute uma dobra fundamental em si mesmo: exerça o poder de se condenar como louco!

A antipsiquiatria, neste caso, não é a recusa dessas práticas: ao inquirir as instituições psiquiátricas e seu saber, não está querendo negar a necessidade de confinamento e tratamento, mas apenas reformulando tais noções. Nesse sentido, já não sabemos se existe um "sofrimento" original e honesto ou se é apenas a fabricação da fraqueza e da "doença" como ideal do poder.

Nas palavras de Nietzsche,

Suposto que a necessidade o force, ele bem que aparece então com uma seriedade de urso, respeitável, esperto, frio, enganadoramente superior, como arauto e porta-voz de poderes mais misteriosos, em meio à outra espécie de animais de rapina, decidido a semear, sobre este chão, sofrimento, discórdia, autocontradição, onde puder, e, seguro até demais de sua arte, tornar-se toda vez senhor sobre sofredores. Ele traz consigo unguento e bálsamo, não há dúvida nenhuma; mas primeiro necessita ferir para depois ser médico; quando, em seguida, aquieta a dor que a ferida causa, ele envenena ao mesmo tempo a ferida - pois disso sobretudo ele entende, esse feiticeiro e domador de animais de rapina, ao redor do qual todo sadio se torna necessariamente doente e todo doente necessariamente manso" (1983, p. 316). 


\section{Referências}

ALTHUSSER, Louis. Por Marx. Campinas: Editora Unicamp, 2015.

DURKHEIM, Emile. As Regras do Método Sociológico. $17^{\mathrm{a}}$ ed. São Paulo: Companhia editora Nacional, 2002.

ELLUL, Jacques. A Técnica e o Desafio do Século. Rio de Janeiro: Paz e Terra, 1968.

EPICURO DE SAMOS. Carta Sobre a Felicidade: a Meneceu. $2^{a}$ reimp. São Paulo: UNESP, 1997.

ESPINOZA, Baruch. Ética. In Os Pensadores. São Paulo: Abril Cultural, 1983.

FOUCAULT, Michel. Ditos \& Escritos. 2ª ed. v. V. Rio de Janeiro: Forense Universitária, 2006a. . História da Loucura na Idade Clássica. 8a ed. São Paulo: Perspectiva, 2008. . História da Sexualidade. 19ª ed. Rio de Janeiro: Editora Graal, 2009.

. O Nascimento da Clínica. 7ª ed. Rio de Janeiro: Forense Universitária, 2012.

. O Poder Psiquiátrico. São Paulo: Martins Fontes, 2006b.

. Vigiar e Punir: nascimento da prisão. Petrópolis: Editora Vozes, 2002.

FROMM, Erich. El Miedo a La Libertad. 2a ed. Buenos Aires: Paidós, 2002. . Psicologia da Sociedade Contemporânea. São Paulo: Circulo do Livro, 1984.

GRAMSCI, Antonio. Escritos Políticos. Rio de Janeiro: Civilização Brasileira, 2004. . Os Intelectuais e a Organização da Cultura. São Paulo: Círculo do Livro, 1985.

HALL, Stuart. A Identidade Cultural na Pós-modernidade. 10ª ed. Rio de Janeiro: LP\&A, 2004.

LAING, Ronald D. La Política de La Experiencia. Barcelona, Espanha: Editorial Crítica, 1977.

LANE, Silvia T. M. Consciência/ Alienação: a ideologia no nível individual. In Psicologia Social: o homem em movimento. 8 a ed. São Paulo: Editora Brasiliense, 1989.

MACHADO DE ASSIS. O Alienista. In Melhores Contos. $15^{\mathrm{a}}$ ed. $1^{\mathrm{a}}$ reimp. Sel. Domício Proença Filho. São Paulo: Global Editora, 2006.

MARCO AURÉLIO. Meditações. In Os Pensadores. São Paulo: Abril Cultural, 1973.

MARCUSE, Herbert. A Ideologia da Sociedade Industrial: o homem unidimensional. $6^{\text {a }}$ ed. Rio de Janeiro: Zahar, 1982.

MARX, Karl. O 18 Brumário de Luís Bonaparte. In Obras Escolhidas Karl Marx e Friedrich Engels. v.1. São Paulo: Alfa-ômega, 1980.

MORIN, Edgar. Cultura de Massas no Século XX: O Espírito do Tempo - I, Neurose. $6^{a}$ ed. Rio de Janeiro: Forense Universitária, 1984.

NIETZSCHE, Friedrich. Para a Genealogia da Moral. $3^{\text {a }}$ ed. In Os Pensadores. São Paulo: Abril Cultural, 1983.

SACADURA ROCHA, José Manuel de. Sociologia Geral e Jurídica: fundamentos e fronteiras. $4^{\mathrm{a}}$ ed. Rio de Janeiro: Forense, 2015.

SZASZ, Thomas S. A Fabricação da Loucura. Rio de Janeiro: Zahar, 1976.

O Mito da Doença Mental. São Paulo: Círculo do Livro, s/d.

VYGOTSKI, Lev S. Obras Escogidas. v. III. Madri, Espanha: Visor Distribuciones, 1995. 